\title{
FABRICATION OF EPOXY COMPOSITE MATERIAL REINFORCED WITH BAMBOO FIBERS
}

\section{Mohamed Khazal Hussain}

Middle Technical University,

Technical Engineering College,

Materials Engineering

Department,

Baghdad, Iraq

\section{Mohamed Abdul Rahman}

Middle Technical University, Technical Engineering College, Mechatronics

Engineering Department,

Baghdad, Iraq

\section{Salman H. Abbas}

Middle Technical University,

Technical Engineering College,

Materials Engineering

Department,

Baghdad, Iraq

\section{Thabit Jamil}

Middle Technical University,

Technical Engineering College,

Power Mechanic

Engineering Department,

Baghdad, Iraq
Younis M. Younis

Middle Technical University,

Technical Engineering College,

Materials Engineering

Department,

Baghdad, Iraq

Key words: polymer matrix composite, bamboo fiber, epoxy, mechanical properties, ultimate tensile strength, impact resistance

Cite article:

Mohamed, K. H., Salman, H. A., Younis, M. Y., Mohamed, A. R., \& Thabit, J. [2021]. Fabrication of epoxy composite material reinforced with bamboo fibers. Journal of Applied Engineering Science, 19(1), 119 - 124. DOI:10.5937/jaes0-26549

Online aceess of full paper is available at: www.engineeringscience.rs/browse-issues 


\title{
FABRICATION OF EPOXY COMPOSITE MATERIAL REINFORCED WITH BAMBOO FIBERS
}

\author{
Mohamed Khazal Hussain ${ }^{1 *}$, Salman H. Abbas', Younis M. Younis', Mohamed Abdul Rahman², Thabit Jamil ${ }^{3}$ \\ ${ }^{1}$ Middle Technical University, Technical Engineering College, Materials Engineering Department, \\ Baghdad, Iraq \\ ${ }^{2}$ Middle Technical University, Technical Engineering College, Mechatronics Engineering Department, \\ Baghdad, Iraq \\ ${ }^{3}$ Middle Technical University, Technical Engineering College, Power Mechanic Engineering Department, \\ Baghdad, Iraq
}

This study aims to enhance the mechanical properties of polymer material using type of natural fiber. Bamboo fiber considered the strongest between the natural fibers group, it have low density, high mechanical strength in addition to its availability makes it economical applicable and have potential for used as engineering material. The study is concerned with evaluate some of the mechanical properties (Tensile strength, Bending strength, Impact strength) for the resultant composite reinforced with 10, 20 and 30 vol.\% of bamboo fibers, as compared with received material. With the natural reinforcement, the optimum mechanical properties in comparison with the as received epoxy were achieved. The results indicated that the tensile strength increased from $13.51 \mathrm{MPa}$ to $33.50 \mathrm{MPa}$ (that is a percentage increase of $150 \%$ ), also the bending strength increased from $24.25 \mathrm{MPa}$ to $44.5 \mathrm{MPa}$ (that is a percentage increase about $83 \%$ ), as well as, the increase of the impact strength from $41 \mathrm{~kJ} / \mathrm{m}^{2}$ to $69 \mathrm{~kJ} / \mathrm{m}^{2}$ (that is a percentage increase about $68 \%$ ).

Key words: polymer matrix composite, bamboo fiber, epoxy, mechanical properties, ultimate tensile strength, impact resistance

\section{INTRODUCTION}

The using of polymeric matrix-composite (PMCs) materials are increased rapidly in both terms of the applications and research [1]. Its benefit over other matters related to specific characteristics investigated such as stiffness and fatigue properties, tensile, bending strengths and impact [2].

Recently, natural fibers are considered as good substitute instead of conventional fibers, mainly the aramid fiber and glass fiber, which utilized in different industrial but also contributing in many problems like "pollution" [3]. Furthermore, they have many advantages such as less of wear in processing equipment, excellent toughness, great strength-to-weight ratio, low abrasiveness, low density and biodegradability [4]. In addition, this type of fiber is considered as "environmentally friendly" due to their neutral characteristic with respect to carbon dioxide emissions, the main responsible for climate changes and global warming [5].

Bamboo, is one of the most applied plants in structural applications, have a stiff culms, unique microstructure and potential to application as ballistic resistant material [6] [7]. Bamboo is also called "grass-type plant" with a strong and rigid culm reaches to, several meters height and more than $8-10 \mathrm{~cm}$ in diameter. Bamboo fibers must be stripped off from its culms and conducted as reinforcement of polymeric material, Therefore, the main disadvantages of bamboo column for direct utilize in engineering applications was its semi cylindrical shape [7]
[8]. Nowadays, bamboo-fiber composites can be considered as a supplement, it will may substitute petroleum based composite materials in many applications, and thus may be displaying consumer, environmental, agriculture and manufacturing new advantages [9].

Several researchers investigated the ability of fabrication epoxy composites reinforced with natural or bamboo fibers to produce composite materials with more cost effective and environment friendly, some of them are Tokoro et al., (2008) investigated in three different kinds of bamboo fiber as alkali treated filament, steam exploded filament and short fiber bundle blend with polylactic acid. Results indicated that there are a new values for highest impact resistance and bending strength [10]. Samal et. al., (2009) assessed the addition of glass-bamboo fiber to the polypropylene matrix. Results revealed that the composites fabricate with $30 \%$ Vol. showed highest mechanical properties, as compared to the received polypropylene. Where the impact resistance, bending strength and the tensile strength increased about $83 \%$, $86 \%$ and $69 \%$ respectively [11]. Gabriel Oliveira Glória et. al. (2015) studied the Charpy energy (impact resistance) of epoxy composites reinforced with 30 vol. \% of bamboo fibers. The impact resistance was increased exponentially with the volume fraction of fiber that incorporated [5]. Renato Batista da Cruz et. al. (2015) evaluated a ballistic properties of a multi-layered armor contain epoxy reinforced with plate of bamboo fibers with a front ceramic tile. Bamboo fiber composite performs as high efficient barrier for the fragments produced from the 
ceramic tile brittle behavior. In the personal protection, this layer performs not only an excellent ballistic performance but also economic benefit and lightness over the synthetic fiber [12]. Khan et al. (2017) prepared epoxy composite reinforced with bamboo fiber using the traditional hand lay-up method, results revealed that composites which having $2.5 \mathrm{~cm}$ fiber length had greater fracture toughness values than resultant composites with short lengths of fiber [13].

This present work, aims to fabricate polymeric composite material based on renewable resource (natural fibers) used as reinforcement material. The resultant composite can be described as a low-cost, viable and alternative with good mechanical properties to polymer materials in different industrial applications.

\section{EXPERIMENTAL WORK}

\section{Materials matrix and reinforcement}

The reinforcing material utilized in this study was the column of giant bamboo supplied from Al-Nasiriya (south of

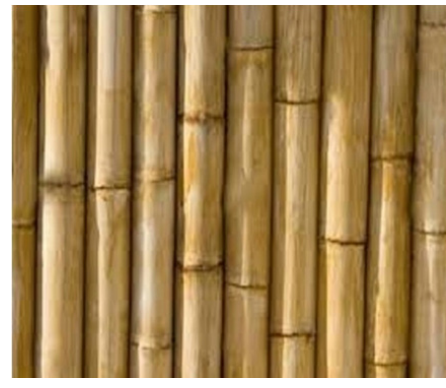

(a)

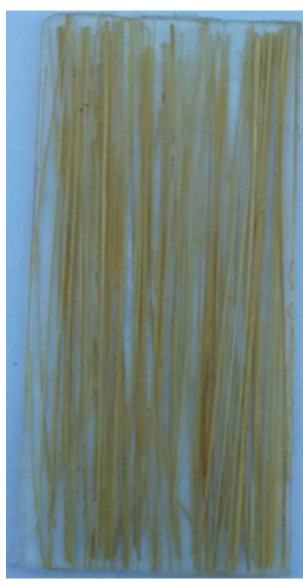

(c)

Figure 1: (a) Bamboo culms, (b) fibers manually stripped off, (c) the composite mold

Iraq). Fig. 1a, shows the as received culms. Fibers were stripped off manually with a sharp blade from the dried culms, as shown in Fig. 1b, bamboo fibers were manually sized into $1 \mathrm{~mm}$ diameter and $200 \mathrm{~mm}$ length. The longitudinal orientation of the fiber match with the column and corresponds to the original direction of the bamboo cellulose fibers. Then, the bamboo fibers that be stripped off were dried in a material laboratory oven in Technical engineering college-Baghdad, at $50{ }^{\circ} \mathrm{C}$ for one day to remove any moisture.

Finally, fibers were soaked in $\mathrm{NaOH}$ solutions at the room temperature for 10 hours. After its alkali treatment, fibers were washed thoroughly with water to neutralize $\mathrm{pH}$, and dried in air for 12 hours, then in oven for 8 hours at 50 ${ }^{\circ} \mathrm{C}$. The chemical treatment methods can be enhance the interfacial adhesion (strength) between the natural fibers and the epoxy matrix. Generally, the modification of bamboo fiber (chemical treatment) are effective method to take off the impurities and remove the bond between the natural fibers in which the resultant composites in various percentage will get the different results of testing. Where, the various techniques required for enhancing adhesion of interfacial surface, refers to the hydrophilic nature of this type of fiber.

In this study, the epoxy matrix was type of Polyprime-Ep, which is the product of Henkel Polybit Industries (UAE). The composite was fabricated using open mould system. A mixing ratio of (2 epoxy: 1 hardener) was selected based on the epoxy manufacturer's guidance. A mold was manufactured inside the material laboratory in the

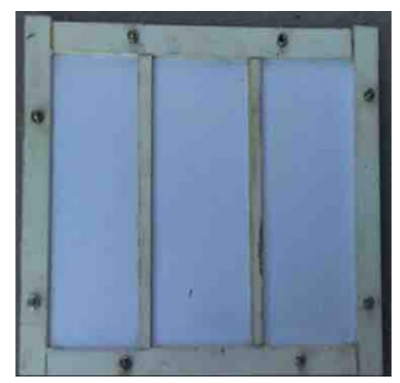

(a)

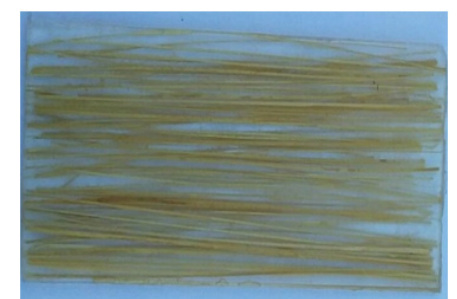

(b)

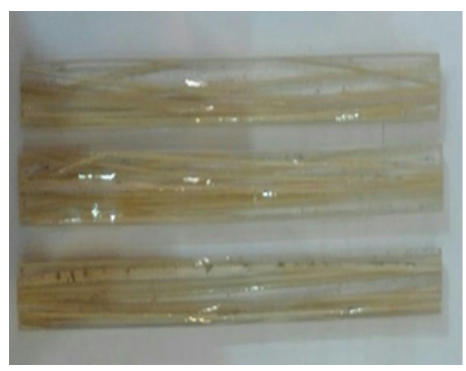

(c)

Figure 2: The mechanical properties specimen mold (a) plastic mold, (b) epoxy-bamboo composite mold, (c) specimen configuration

technical engineering college, consists of a plastic base surrounded with four panel from outside, and divided inside into three parts represent three fiber volume fractions $(10,20,30) \%$ respectively, that are to be investigated. The resulted composite panel would be taken out after 1 day to fully solidification, then after 14 days curing time they were ready to be cut and tested. The panel dimension were $(4 \times 100 \times 200) \mathrm{mm}$, which were to be cut for the required dimensions for the bending, tensile, and impact test specimens, as in Fig. 2. 


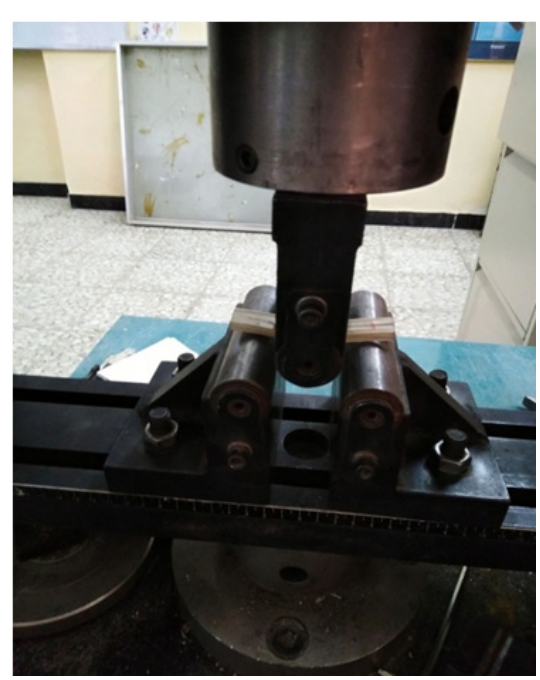

(a)

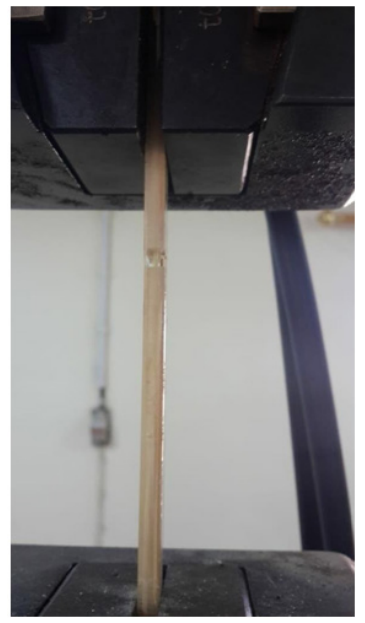

(c)

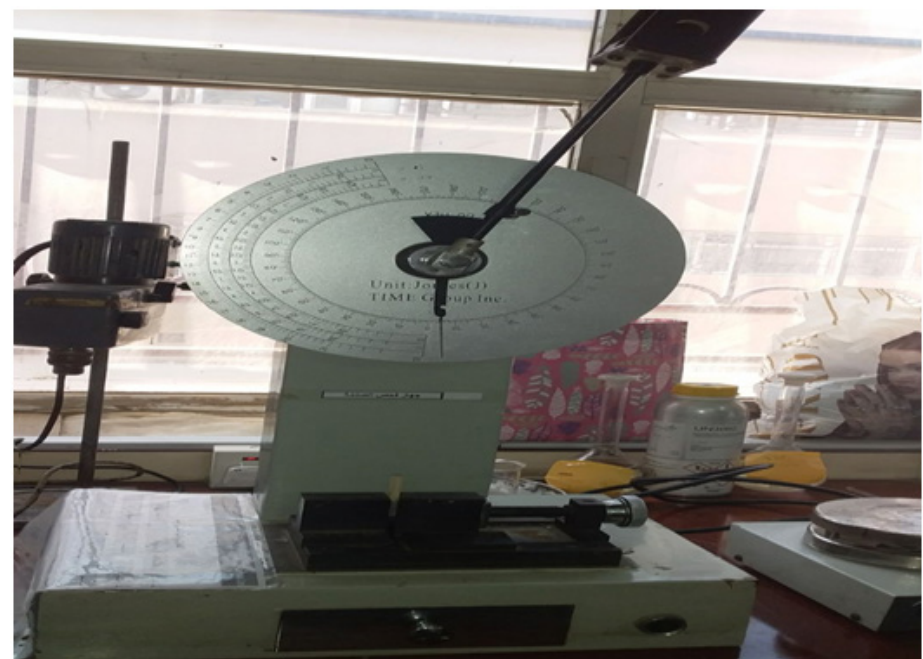

(b)

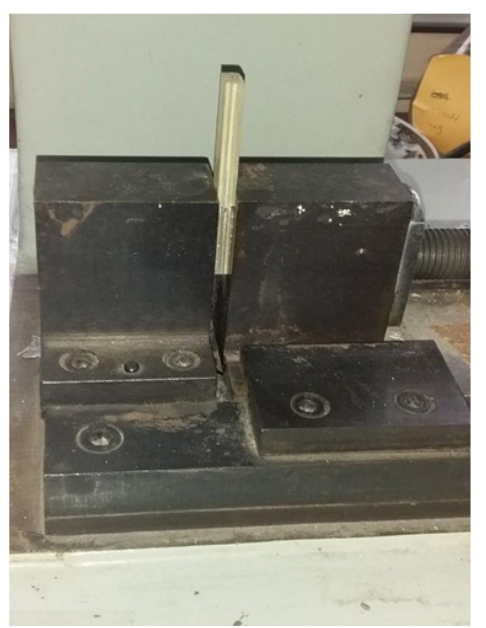

(d)

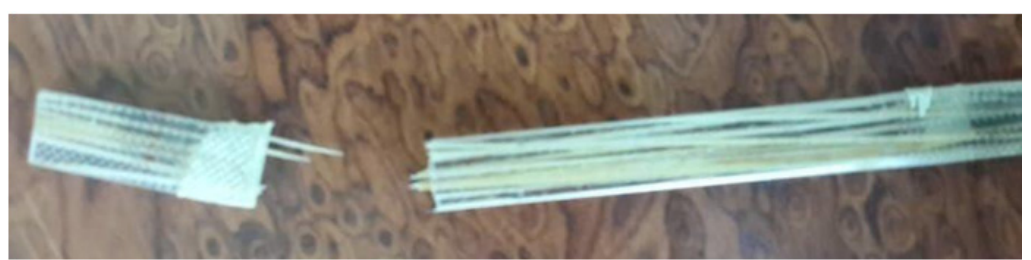

(e)

Figure 3: Mechanical testing device: (a) bending tester, (b) impact resistance tester machine, (c) universal machine, (d) specimen during impact test, (e) specimen after tensile test

\section{Mechanical testing}

Tensile test: the specimens were cut to according to ASTM D3039 standardization, and this test was performed in the Institute of Technology at Baghdad

Bending test: the specimens were cut to according to ASTM D790 standardization, as shown in Fig. 3. This test was performed on the same universal tester.

Impact test: the specimens were cut to according to (ISO 179-1982 E). This test was carried at the applied science department of the University of Technology, as shown in Fig. 3.

\section{RESULTS AND DISCUSSIONS}

The mechanical properties for this type of composite may be affected by different factors such as: fiber length, fiber aspect ratio, fibers volume fraction, orientation of fibers and the adhesion between fibers and matrix.

\section{Tensile test results}

The ultimate tensile strength (UTS) and (stress - strain curve) of the resultant bamboo composite as compared with received epoxy are shown in Fig. 4. The resultant composite materials that reinforced with $(10 \%, 20 \%$ and $30 \%$ bamboo fiber) have an ultimate tensile strength higher than that of the epoxy matrix material. 
From the results of UTS, it can be seen that the relation between stress and bamboo fiber percent is not linear, where, the results indicate strength of the resultant composite increased dramatically as the natural fiber content increased, as shown Fig. 4 which explains the relation between the UTS and Vol\% of the bamboo fiber. Practically, the tensile strength increased from $13.50 \mathrm{~N} / \mathrm{mm}^{2}$ of the as received epoxy, and reached to around $21.45 \mathrm{~N} / \mathrm{mm}^{2}$ at $10 \%$ fiber volume fraction, and to $28.17 \mathrm{~N} / \mathrm{mm}^{2}$ at $20 \%$ fiber volume fraction, and finally to around $33.59 \mathrm{~N} / \mathrm{mm}^{2}$ at $30 \%$ fiber volume fraction. This increment may be due to that the bamboo fiber have high tensile strength with respect to its weight, which originate from the longitudinal alignment of fibers in its body, and this makes bamboo fiber an attractive substitute to metals (such as steel or other alloy) in the application of tensile loading.

Indeed, all the specimens at the failure shown that the resultant composite displays less fragments and good adhesion between fibers and matrix, as shown in Fig. 3 $c$ and e. Furthermore, the bamboo epoxy composite is significantly lighter and less expensive than other type of fiber like aramid fabric. These reasons might be considered as practical benefits in favor of bamboo epoxy composites over other type like aramid fabric plies [12].

\section{Bending test}

In this test, most of the specimens failed without breaking up into two or more pieces due to the strong bonding that formed between the epoxy and the bamboo fibers. The other point is that for the variables in this test, the $10 \%$ fiber vol. \% were not as effective as for the other vol. $(20,30) \%$, and it looks that, increasing the volume fraction more, the effect of bamboo reinforcement would be even more apparent because the improvement in interfacial bonding between matrix and fibers. The bending strength increased from $24.25 \mathrm{~N} / \mathrm{mm}^{2}$ of the as received epoxy, and reached to around $30.3 \mathrm{~N} / \mathrm{mm}^{2}$ at $10 \%$ fiber volume fraction, and to $36.6 \mathrm{~N} / \mathrm{mm}^{2}$ at $20 \%$ fiber volume fraction, and finally to around $44.55 \mathrm{~N} / \mathrm{mm}^{2}$ at $30 \%$ fiber volume fraction, as shown in Fig. 5 which are shown the relation between the fiber volume fraction and the bending strength of the resultant composite as compared with received epoxy matrix. As mention previously, natural fibers like bamboo have higher mechanical properties such as stiffness, flexibility and modulus, than epoxy matrix. Therefore, it is easy to understand that the fiber length and higher fiber content could provide higher flexural stiffness during the bending test.

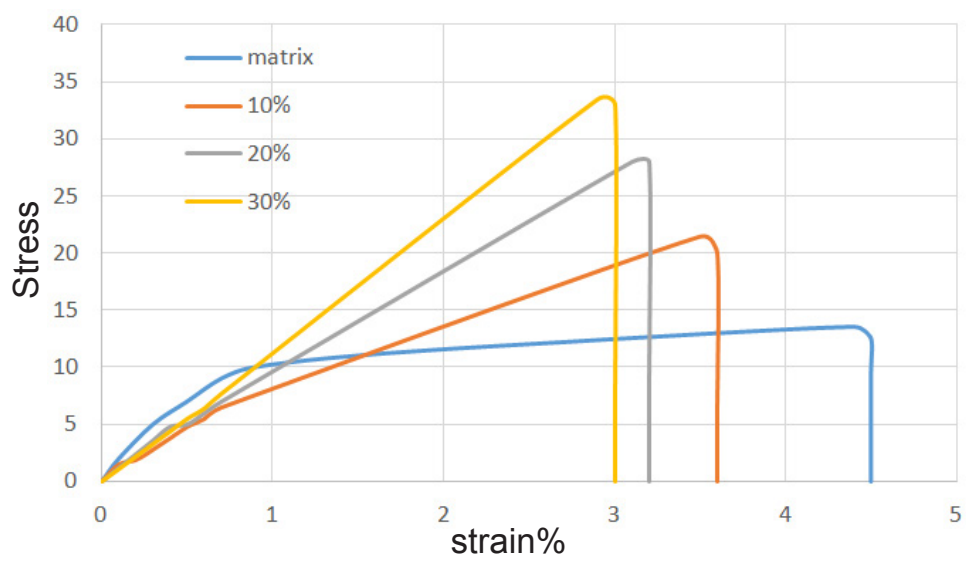

Figure 4: stress-strain curves (tensile stress behavior) of composite with 10, 20, $30 \%$ bamboo Vol. fraction as compared with received matrix

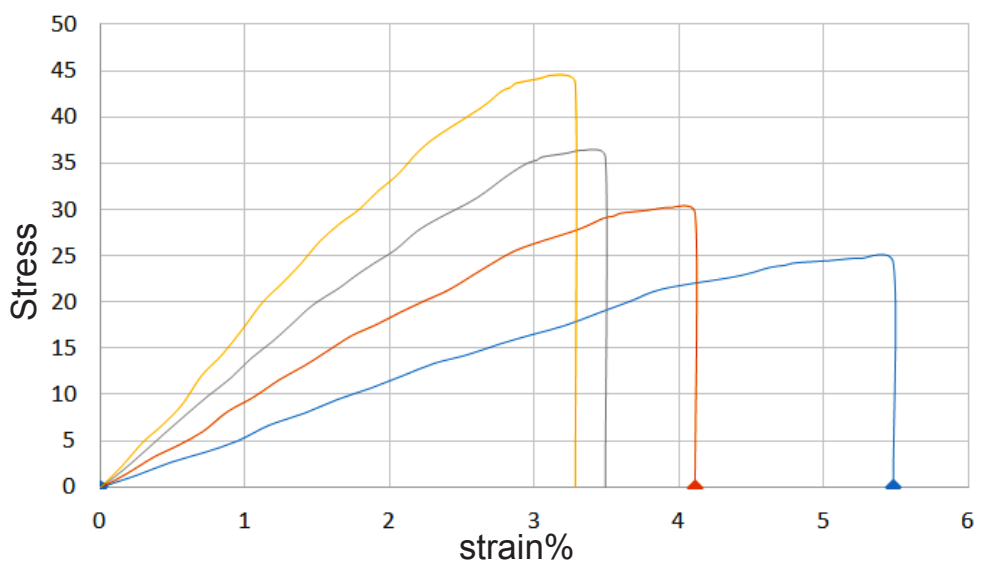

Figure 5: stress-strain curves (bending stress behavior) of composite with 10, 20, $30 \%$ bamboo Vol. fraction as compared with received matrix 
80

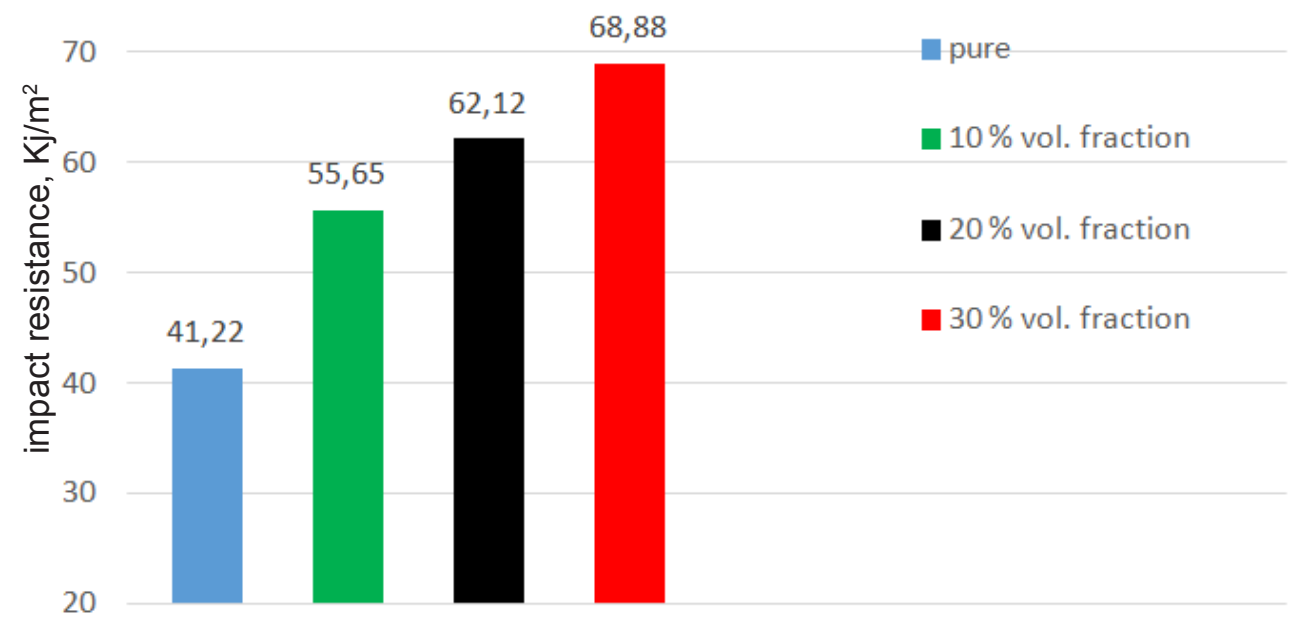

Figure 6: Impact test results

However, results might be enhance more, where, specimens showed negligible differences in bending strength. This state revealed that the bamboo fibers may be not act effectively as reinforcements to the resin. In this case, the bending strength of the resultant composites was still controlled by the epoxy matrix properties. This was mainly attributed to the fact that bamboo fibers were randomly oriented in the epoxy matrix at low volume fraction. That's, could be explained by the fact that the low fibers content cause non uniform distribution, thus acting as defects initiation, resulting in the decrease of flexural strength [12].

\section{Impact test}

Experimentally, the bamboo composites may be have a relatively lower impact resistance (Charpy toughness), because that bamboo was manually extracted from the hard column by using a sharp blade. This certainly produces relatively many defects and disorder in the micro fibers that constitute each fiber [14].

Fig. 6 shows the relation between impact energy and volume fraction of the bamboo fibers that reinforcing epoxy matrix composites. It can be seen that, as the bamboo fibers content increased, the impact energy increased too. Where, The impact energy absorbed increased from $41.22 \mathrm{~kJ} / \mathrm{m}^{2}$ of the pure epoxy, reached to $55.65 \mathrm{~kJ} / \mathrm{m}^{2}$ at $10 \%$ fiber volume fraction, and to $62.12 \mathrm{~kJ} / \mathrm{m}^{2}$ at $20 \%$ fiber volume fraction, finally to around $68.88 \mathrm{~kJ} / \mathrm{m}^{2}$ at $30 \%$ fiber volume fraction, these increment due to the adhesion characteristics that results between the bamboo fibers and epoxy resin matrix. From other hand, the enhancement in the impact resistance can be attributed to the "de-cohesion" of the matrix/fiber low shearing stress interface and tension rupture of the micro fibers. These behaviors result in higher energy absorbed, as a result to longitudinal propagation of multiple cracks and different broken zones of the numerous micro fibers [5]. In this test in can be clearly seen that, rupture is predomi- nantly transversal to the samples length and nucleates at the center, as expected. In the as received epoxy a "flat fracture" surface is demonstrated, while for the case of composites specimens, fibers are shown sticking out of the sample broken surface. This revealed that the crack initiated upon the hammer impact, then propagates across the brittle epoxy resin but is stopped at the bamboo fibers interface. The crack either changes its direction or nucleates another new cracks in between fiber epoxy interface. Consequently, cracks will propagated longitudinally along the fibers interfacial length, then, a greater fracture zone is created in association with higher impact energy [15].

\section{CONCLUSIONS}

The concluding remarks derived from this experimental work can be concise as follows:

- Resultant composites of epoxy matrix reinforced with 10,20 and $30 \%$ of aligned and continuous bamboo fibers produce an exponential increase in mechanical performance as a function of the fibers volume fraction increased.

- Ultimate Tensile Strength was highly enhanced within bamboo fibers reinforcement, where it increased about $150 \%$ as compared with as received epoxy.

- The bending strength and impact resistance of the resultant composite increased about $83 \%$ and $68 \%$ respectively, as compared with received epoxy.

- The increment can be attributed to the unique properties of bamboo fiber which have good mechanical properties, as well as to a good interfacial adhesion between bamboo fiber and epoxy matrix.

\section{ACKNOWLEDGEMENT}

The authors would like to acknowledge with gratitude to Miss Sarah Khalid and Miss Hadeel Kamel, due to their important contribution to accomplish this research. 


\section{REFERENCES}

1. Kannan, R., Ahmad, M. (2013). A review on mechanical properties of bamboo fiber reinforced polymer composite. Australian Journal of Basic and Applied Sciences, vol. 7, no. 8, pp. 247-253.

2. Athijayamani, A., Thiruchitrambalam, M., Manikandan, V., Pazhanivel, B. (2010). Mechanical properties of natural fibers reinforced polyester hybrid composite. International Journal Plastic Technology, vol. 14, no. 1, pp. 104-116.

3. Dweib, A., Hu, B., O'donnell, A., Shenton, W., Wool, P. (2004). All natural composite sandwich beams for structural applications. Composite Structures, vol. 63, no. 2, pp. 147-157, DOI:10.1016/S02638223(03)00143-0.

4. Monteiro, S., Lopes, F., Barbosa, A., Bevitori, A., Da Silva, I., Da Costa, L. (2011). Natural lignocellulosic fibers as engineering materials-an overview. Metallurgical and Materials Transactions A, Physical Metallurgy and Materials Science, vol. 42, no. 10, pp. 2963-2974, DOI:10.1007/s11661-011-0789-6.

5. Glória, G., Margema, F., Ribeiroa, C., de Moraesa, Y., da Cruzb, R., Silvac, F., Monteirob, S. (2015). Charpy impact tests of epoxy composites reinforced with giant bamboo fibers. Materials Research, vol. 18, pp. 178-184, DOI: org/10.1590/1516-1439.360614.

6. Okubo, K., Fujii, T., Yamamoto, Y. (2004). Development of bamboo-based polymer composites and their mechanical properties. Composites Part A, Applied Science and Manufacturing, vol. 35, no. 3, pp. 377-383, DOI: 10.1016/j.compositesa.2003.09.017.

7. Okubo, K., Fujii, T., Yamashita, N. (2005). Improvement of interfacial adhesion in bamboo polymer composite enhanced with micro-fibrillated cellulose. International Journal Series A Solid Mechanics and Material Engineering, vol. 48, no. 4, pp. 199-204, 2005, DOI: org/10.1016/j.compositesa.2003.09.017.

8. Costa, L., Monteiro, S., Loiola, R. (2010). Mechanical behavior of polyester composites reinforced with continuous bamboo fibers. Proceedings of the Characterization of Minerals, Metals \& Materials-TMS Conference 2010, pp. 1-6.
9. Burgueno, R., Quagliata, M., Mohanty, A., Mehta, G., Drzal, L., Misra, M. (2005). Hybrid biofiber-based composites for structural cellular plates. Composite Part A: Applied Science and Manufacturing, vol. 36, no. 5, pp. 581-593, DOI: org/10.1016/j.compositesa.2004.08.004.

10. Tokoro, R., Vu, D., Okubo, K., Tanaka, T., Fujii, T., Fujiura, T. (2008). How to improve mechanical properties of polylactic acid with bamboo fibers. Journal of Material Science, vol. 43, no. 2, pp. 775-787, DOI: 10.1007/s10853-007-1994-y.

11. Samal, S., Mohanty, S., Nayak, S. (2009). Polypropylene-bamboo/glass fiber hybrid composites: fabrication and analysis of mechanical, morphological, thermal, and dynamic mechanical behavior. Journal of Reinforced Plastics and Composites, vol. 28 , no. 22 , pp. 2729-2747, DOI: org/10.1177/0731684408093451.

12. da Cruz, R., Junior, E., Monteiro, S., Louro, L. (2015). Giant bamboo fiber reinforced epoxy composite in multilayered ballistic armor. Materials Research, vol. 18, pp. 70-75, DOI: org/10.1590/15161439.347514.

13. Khan, Z., Yousif, B., Islam, M. (2017). Fracture behaviour of bamboo fiber reinforced epoxy composites. Composite Part B: Engineering, vol. 116, pp. 186-199, DOI:10.1016/j. compositesb.2017.02.015.

14. Martins, L., Margem, F., Monteiro, S., Loyola, R., Margem, J. (2014). Izod Impact Tests of Polyester Composites Reinforced with Bamboo Fibers of the Specimen Dendrocalmus Giganteus. Characterization of Minerals, Metals, and Materials 2014, pp. 581-587, DOI: 10.1002/9781118888056.ch54.

15. Fu, S., Lauke, B., Mäder, E., Hu, X., Yue, C. (1999). Fracture resistance of short-glass-fiber-reinforced and short-carbon-fiber-reinforced polypropylene under Charpy impact load and its dependence on processing. Journal of Materials Processing Technolgy, vol. 89, pp. 501-507, DOI: org/10.1016/S09240136(99)00065-5. 